\title{
THE ROLE OF EMPLOYEE MOTIVATION FACTOR ON ORGANIZATIONAL PERFORMANCE: A CASE STUDY OF EDUCATION SECTORS IN KURDISTAN
}

\author{
Nawroz Ahmed Abdulrahman
}

Erbil Polytechnic University

Erbil-Kurdistan

\begin{abstract}
The research examines the role of motivation factors on organizational performance and particularly education sectors in Erbil. The study aims to determine the factors employee motivation that the most has role in education sector's outcome. A quantitative research method employed to find out the most and the least employee motivation factors. However, the researcher distributed hard copy of surveys to the both administrative and academic staffs of education sectors in Erbil. From 200 surveys only 189 surveys have been fulfilled correctly. The findings revealed that recognition is the most influence motivation factors on education sectors' outcome on the other hand job security is the least most influence motivation factors on education sectors' outcome.
\end{abstract}

Keywords: Education section, Employee motivation, Kurdistan, Organizational performance

\section{INTRODUCTION}

The best way to inspire individuals to like buckling down is to spur them. Today, individuals must comprehend why they're buckling down. Each person in an education sectors is persuaded by some extraordinary way. When talking in term of labor inspiration, it can be just characterized as "Worker inspiration is an impression of the level of vitality, duty, and inventiveness that an organization's laborers convey to their occupations." The activity of a supervisor in the work environment is to complete things through labors. To do this the administrator ought to have the capacity to propel workers (Jin, et al., 2018). Yet, that is less demanding said than done! Inspiration practice and hypothesis are troublesome subjects, addressing a few controls. Disregarding huge research, essential and in addition connected, the subject of inspiration isn't plainly 
comprehended and as a rule inadequately rehearsed. To comprehend inspiration, one must comprehend human instinct itself. Furthermore, there lies the issue! Human instinct can be exceptionally basic, yet extremely complex as well. A comprehension and energy about this is an essential to successful labor inspiration in the working environment and hence powerful administration and initiative. Each labor or laborer has his or her arrangement of inspirations and individual motivating forces that ginger him or her to buckle down or not all things considered. Some are roused by acknowledgment while others are propelled with money motivating forces (Selvarajan, et al., 2018).

Inspiration of labors in the work put still stays one of the touchy subjects that decide the level of info that workers will put in the education sectors to focus on great performance. This implies inspiration either natural or extraneous add to labor fulfillment and hence upgrades performance and efficiency and it is communicated by (Alnawafleh, et al., 2018) that in the twenty-first century, treating individuals right isn't an alternative however a need. This was stressed by (Kim, 2018) that, the way an organization deals with its workforce decides its capacity to build up and keep up an upper hand over different organizations.

Individuals have distinctive necessities that are ceaselessly contending with each other and change with a person. Every individual has an alternate blend and quality of necessities, as a few people are driven by accomplishment while others are concentrating on security. On the off chance that the administrators/chiefs can comprehend, anticipate and control worker conduct, they ought to likewise realize what the labors need from their employments. Consequently, it is fundamental for a director/administrator to comprehend what truly inspires labors without making a presumption (Vakharia, et al.,2018). Inspiration as expressed by (Van Iddekinge, et al., 2018) is for the most part characterized as the procedure that records for an individual's power, course, and industriousness of exertion toward accomplishing an objective. It was likewise portrayed by (Wang, 2018) as the quality and course of conduct, these three ideas can be referred to as how hard be the individuals" endeavors and for to what extent they are kept up. In specific occasions, inspiration can fill in as the clarification and the forecast of conduct of a specific individual's work performance. Inspiration alludes to "the reasons basic conduct" (Subramony, et al., 2018). Inborn inspiration is inspiration that is vivified by individual delight, intrigue, or joy. Inborn inspiration empowers and manages exercises through the unconstrained fulfillments inalienable in powerful volitional activity. It is show in practices, for example, play, investigation, and test looking for those individuals frequently improve the situation outer prizes. Scientists frequently balance natural inspiration with outward inspiration, which is inspiration administered by fortification possibilities (Simajuntak \& Tobing, 2018). For accomplishing thriving, education sectors outline distinctive procedures to rival 
the contenders and for expanding the performance of the education sectors. A not very many education sectors trust that the human faculty and labors of any education sectors are its primary resources which can lead them to progress or if not concentrated well, to decay. Unless and until, the workers of any education sectors are happy with it, are persuaded for the undertakings satisfaction and objectives accomplishments and supported, none of the education sectors can advance or make progress. With a specific end goal to accomplish their objectives and destinations, education sectors create procedures to contend in profoundly focused markets and to expand their performance. By the by, only a couple of education sectors think about the human capital just like their primary resource, fit for driving them to progress or if not oversaw appropriately, to decrease. On the off chance that the labors are not happy with their employments and not propelled to satisfy their assignments and accomplish their objectives, the education sectors can't achieve achievement (Wen Lim, et al., 2018).

Specialists have a tendency to perform all the more viably if their wages are identified with performance which did not depend on individual predisposition or partiality, however on target assessment of a labor's legitimacy. In spite of the fact that few method of estimating work performance has been created, by and large, the particular procedure picked fluctuates with the kind of work. For accomplishing flourishing, education sectors outline diverse techniques to contend with their adversaries and for expanding the performance of the education sectors. A not very many education sectors trust that the human work force and labors of any education sectors are its principle resources which can lead them to progress or if not concentrated well, to decrease. Unless and until, the labors of any education sectors are happy with it, are propelled for the undertakings satisfaction and objectives accomplishment and energized, none of the education sectors can advance or make progress (Mikkelsen, et al., 2017 ). Every one of these issues call for inquire about endeavors, in order to convey to concentrate how a fitting prize bundle can scoff up or impact specialists to create uplifting disposition towards their activity and subsequently increment their profitability. Diversity at work environment has furnished chiefs with considerable extent of issues; the enormous distinction between labors in each education sectors implies that there is no most ideal approach to manage such issue. What persuades some labor to perform might demoralize to other worker; subsequently it represents a major test to show day administrators. In this postulation, culture in human asset administration is talked about and additionally performance administration and distinctive kind of motivation framework (Siddiqui \& Bisaria, 2018). 


\section{Conceptual framework}

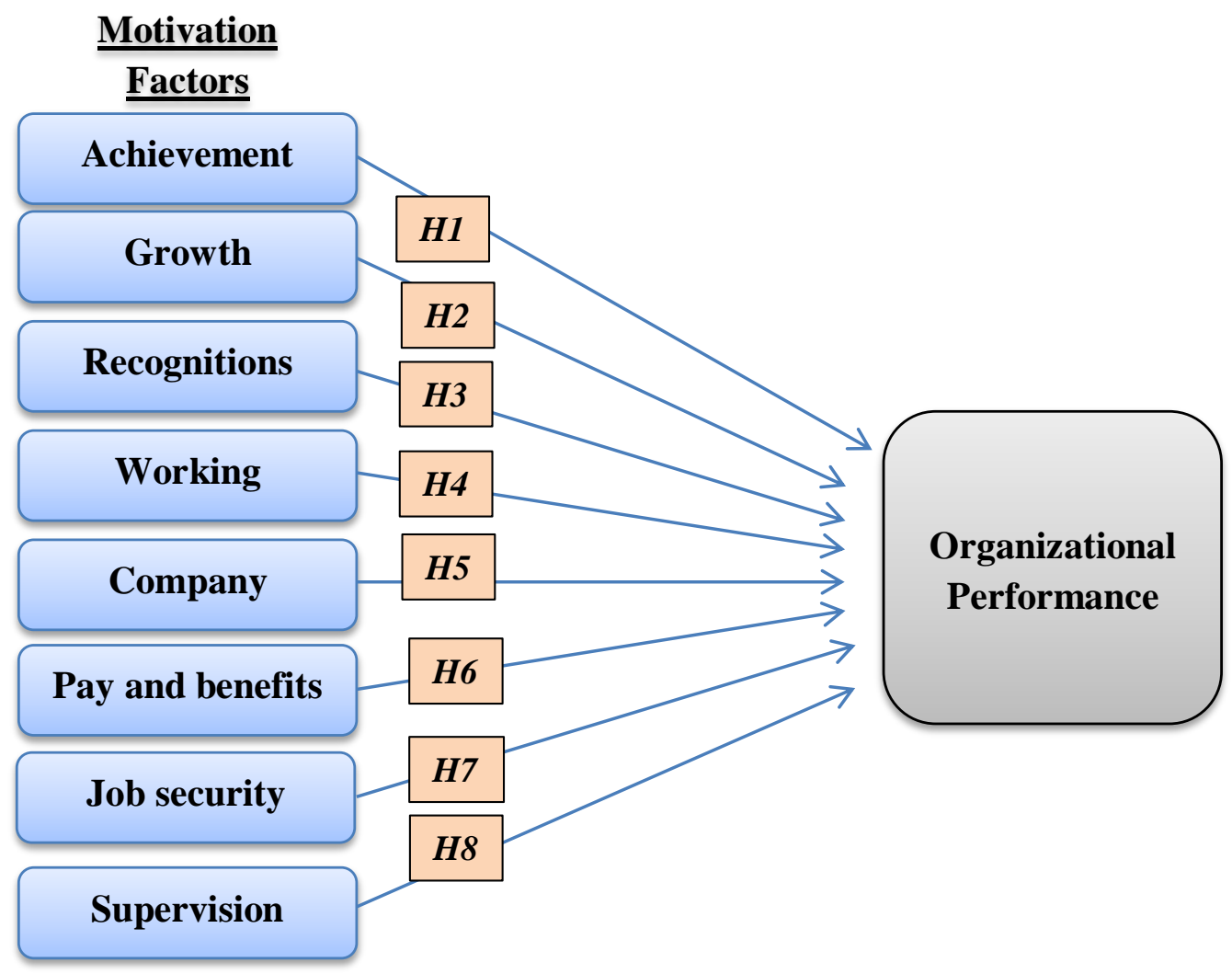

Figure 1- RESEARCH MODEL

\section{Hypotheses}

As stated in the research model (figure-1-), the researcher developed eight research hypotheses to investigate the factors affecting employee motivation on organizational performance in education sectors in Kurdistan, accordingly the researcher developed the following research hypotheses:

Research Hypothesis -1-: Employee achievement as a motivation factor has a significant and positive role on organizational performance.

Research Hypothesis -2-: Growth as a motivation factor has a significant and positive role on organizational performance.

Research Hypothesis -3-: Recognition as a motivation factor has a significant and positive role on organizational performance. 
Research Hypothesis -4-: Working condition as a motivation factor has a significant and positive role on organizational performance.

Research Hypothesis -5-: Company policy as a motivation factor has a significant and positive role on organizational performance.

Research Hypothesis -6-: Pay and benefit as a motivation factor has a significant and positive role on organizational performance.

Research Hypothesis -7-: Job security as a motivation factor has a significant and positive role on organizational performance.

Research Hypothesis -8-: Supervision as a motivation factor has a significant and positive role on organizational performance.

\section{LITERATURE REVIEW}

\section{The concept of motivation}

Motivation is a term subjected to multidimensional definitions. It alludes to conditions that decide why individuals do or cease from getting things done (Jensen, 2018). Motivation is for the most part separate as a standout amongst the most compelling indicators of individual conduct and a key expert of performance for basic part of conduct. Labor inspiration has a critical influence inside education sectors (Mills, 2017). For example, worker inspiration can be a central point with labor performance. Labors that are more spurred have a tendency to perform better, for example, accomplishing more work in less time (Porter, et al.,2016). Worker performance is imperative on the grounds that authoritative achievement or disappointment is frequently reliant upon how much exertion labors set forth while finishing their activity undertakings. Taken together, the procedure of inspiration includes picking elective type of activity so as to accomplish some coveted finishes or objectives. Inspiration is the main impetus to seek after and fulfill ones needs (Devito, et al.,2016). On the off chance that workers don't perform well, the education sectors will create less for indistinguishable expenses of work from roused labors however will have less generation than inspired workers. Thus, the education sectors will probably experience issues profiting and paying their costs (Mikkelsen, et al.,2017).

Encouraging workers is imperative for an education sectors in light of the fact that spurred labors enhance the education sector's performance; dependably search for better approach for getting things done; focus more on quality which is valuable to the education sectors; are more beneficial, are objective coordinated and act in a purposive way (Njoroge \& Yazdanifard, 2014). Inspiration assumes a focal part in any administrator's activity. 
Since administration includes getting an education sector's targets accomplished through the participation and joint effort of individuals, keeping their confidence up in fundamental to securing their dedication and excitement (Ahmad, et al., 2014). Subsequently, it isn't stunning that inspiration appear in a scope of direction paper, researchers and administrators have immense consideration in tolerating individual inspiration to utilize collective medium and devices for the benefit of organizations (Gopal \& Chowdhury, 2014).

\section{Organizational performance}

Performance is ordinarily the vehicle behind which the hierarchical objectives and destinations are converted into an individual's objective (Lau \& Roopnarain, 2014). Following worker preparing and estimating preparing adequacy is a key target of any HR office. The greater part of late writing on Performance expresses that it should be completed as a major aspect of an entire Performance Management framework and none exclusively all alone (Khuong \& Hoang, 2015). Performance Management as the "process of guiding and supporting labors to fill in as adequately and productively as conceivable in accordance with the necessities of the organization ${ }^{e}$. At the point when a piece of performance administration, evaluation is substantially more firmly connected with the bigger business condition. Performance administration alludes to a general arrangement of exercises which are done by the education sectors to enhance labor performance (Kuranchie-Mensah \& Amponsah-Tawiah,2016). Zameer, et al., (2014), trust the thought of Performance Management is making a mutual vision of the points and motivation behind the education sectors, helping every individual labor to comprehend and perceive their part in adding to them, and in this manner overseeing and enhancing the performance of the two people and the education sectors. A decent worker performance is fundamental for the education sectors, since an education sectors' prosperity is reliant upon the labor's imagination, development and duty (Jin, et al., 2018). To guarantee that there is sufficient quantifiable profit in preparing of new and current workers, the education sectors needs to set up key performance markers. It likewise remains the essential method for examining and following up on the advancement of the individual (Vakharia, et al., 2018). Despite the fact that performance administration is commonly dependent on performance evaluations, performance administration is a more extensive and additionally enveloping procedure and is a definitive objective of performance examination exercises (Subramony, et al., 2018). The fundamental target of performance evaluation is to build the performance of labors that will look forward toward accomplishment of education sectors. Performance Management has been believed to be more effective and conveys a ton of advantages to an education sectors (Wen Lim, et al., 2018). Performance administration frameworks are compelling when they depend on objectives that are mutually set and are driven by an education sector's business technique (Mikkelsen, et al., 2017). 
Performance from a social-mental point of view instead of the conventional instrument for estimation is ending up more well known, seeing Performance as a correspondence and social process (Siddiqui \& Bisaria, 2018). Performance measurement if made and followed legitimately fills in as a benchmark for estimating the advance of workers towards an arrangement of more extensive based objectives or targets (Mills, 2017). Great job exhibitions and profitability development are likewise essential in balancing out our economy; by methods for enhanced expectations for everyday comforts, higher wages, an expansion in merchandise accessible for utilization, and so on (Porter, et al., 2016). Performance of labor is the greatest wellspring of authoritative adequacy and Performance of workers is increments through powerful examination framework (Devito, et al., 2016).

\section{METHODOLOGY}

The study was carried out at education sectors in Kurdistan and particularly in Erbil. The researcher intended to find the most of important motivation factor that has role in education sectors' performance in Erbil. However, the researcher printed and distributed hard copy of questionnaire to the both administrative and academic staffs of education sectors in Erbil. The researcher distributed 200 surveys, but only 189 surveys have been fulfilled correctly. The researcher employed a quantitative research method to examine the most significant motivation factor and its effect on education sectors in Erbil.

\section{FINDINGS}

\section{Reliability analysis}

The reliability analysis implemented to examine the reliability of items used to measure the organizational performance (as seen in table-1-). Based on the research model (as seen in figure-1-), the researcher developed eight research hypotheses through using eight motivation factors as independent variables to measure organizational performance as dependent variable. Moreover, the findings of the reliability analysis were as follow:

- As for employee achievement as motivation factor, the alpha was found to be .799 for 8 questions used in the analysis.

- As for employee growth as motivation factor, the alpha was found to be .732 for 9 questions used in the analysis.

- As for recognition as motivation factor, the alpha was found to be .812 for 9 questions used in the analysis.

- As for working condition as motivation factor, the alpha was found to be .802 for 8 questions used in the analysis. 
- As for company policy as motivation factor, the alpha was found to be .734 for 8 questions used in the analysis.

- As for pay and benefit as motivation factor, the alpha was found to be .799 for 9 questions used in the analysis.

- As for job security as motivation factor, the alpha was found to be .712 for 8 questions used in the analysis.

- As for supervision as motivation factor, the alpha was found to be .781 for 9 questions used in the analysis.

- As for organizational performance as dependent variable, the alpha was found to be .801 for 9 questions used in the analysis.

However, the findings of reliability analysis revealed that all alpha's value were above 0.7 for all variables, this demonstrated that all questions employed for the current study were reliable.

Table 1- Reliability analysis

\begin{tabular}{ccc}
\hline Variables & Cronbach's Alpha & Items \\
\hline Achievement & .799 & 8 \\
\hline Growth & .732 & 9 \\
\hline Recognition & .812 & 9 \\
\hline Working condition & .802 & 8 \\
\hline Company policy & .734 & 8 \\
\hline Pay and benefit & .799 & 9 \\
\hline Job security & .712 & 8 \\
\hline Supervision & .781 & 9 \\
\hline $\begin{array}{c}\text { Organizational } \\
\text { performance }\end{array}$ & .801 & 9
\end{tabular}

Source; author, 2018

\section{Correlation Analysis}

The correlation analysis employed to measure the relationship between variables, as seen in table -2- the correlation between eight motivation factors as independent variables with organizational performance in education sectors as dependent variable. The findings of correlation analysis were as follow:

- The value of correlation between achievement as motivation factor and organizational performance in education sector $=.686^{* *}$, as we know that $\left({ }^{* *}\right)$. Correlation is significant at the 0.01 level (2-tailed), therefore it was found that there is a positive and strong correlation between achievement as motivation factor and organizational performance in education sector. 
- The value of correlation between growth as motivation factor and organizational performance in education sector $=.611^{* *}$, as we know that $(* *)$. Correlation is significant at the 0.01 level (2-tailed), therefore it was found that there is a positive and strong correlation between growth as motivation factor and organizational performance in education sector.

- The value of correlation between recognition as motivation factor and organizational performance in education sector $=.798^{* *}$, as we know that $(* *)$. Correlation is significant at the 0.01 level (2-tailed), therefore it was found that there is a positive and strong correlation between recognition as motivation factor and organizational performance in education sector.

- The value of correlation between working condition as motivation factor and organizational performance in education sector $=.702^{* *}$, as we know that $\left.{ }^{* *}\right)$. Correlation is significant at the 0.01 level (2-tailed), therefore it was found that there is a positive and strong correlation between working condition as motivation factor and organizational performance in education sector.

- The value of correlation between company policy as motivation factor and organizational performance in education sector $=.674^{* *}$, as we know that $\left({ }^{* *}\right)$. Correlation is significant at the 0.01 level (2-tailed), therefore it was found that there is a positive and strong correlation between company policy as motivation factor and organizational performance in education sector.

- The value of correlation between job security as motivation factor and organizational performance in education sector $=.674^{* *}$, as we know that $(* *)$. Correlation is significant at the 0.01 level (2-tailed), therefore it was found that there is a positive and strong correlation between job security as motivation factor and organizational performance in education sector.

- The value of correlation between pay and benefit as motivation factor and organizational performance in education sector $=.711^{* *}$, as we know that $\left({ }^{* *}\right)$. Correlation is significant at the 0.01 level (2-tailed), therefore it was found that there is a positive and strong correlation between pay and benefit as motivation factor and organizational performance in education sector.

- The value of correlation between supervision as motivation factor and organizational performance in education sector $=.675^{* *}$, as we know that $\left({ }^{* *}\right)$. Correlation is significant at the 0.01 level (2-tailed), therefore it was found that there is a positive and strong correlation between supervision as motivation factor and organizational performance in education sector. 
Table 2- Correlations Analysis

\begin{tabular}{|c|c|c|}
\hline Factors & Correlation & Organizational performance \\
\hline \multirow{3}{*}{ Achievement } & Correlation & $.686^{* *}$ \\
\hline & $\begin{array}{l}\text { Sig. (2- } \\
\text { tailed) }\end{array}$ & .000 \\
\hline & $\mathrm{N}$ & 189 \\
\hline \multirow[t]{3}{*}{ Growth } & Correlation & $.611^{* *}$ \\
\hline & $\begin{array}{l}\text { Sig. (2- } \\
\text { tailed) }\end{array}$ & .000 \\
\hline & $\mathrm{N}$ & 189 \\
\hline \multirow[t]{3}{*}{ Recognition } & Correlation & $.798^{* *}$ \\
\hline & $\begin{array}{l}\text { Sig. (2- } \\
\text { tailed) }\end{array}$ & .000 \\
\hline & $\mathrm{N}$ & 189 \\
\hline \multirow{3}{*}{$\begin{array}{l}\text { Working } \\
\text { condition }\end{array}$} & Correlation & $.702^{* *}$ \\
\hline & $\begin{array}{l}\text { Sig. (2- } \\
\text { tailed) }\end{array}$ & .000 \\
\hline & $\mathrm{N}$ & 189 \\
\hline \multirow[t]{3}{*}{ Company policy } & Correlation & $.674^{* *}$ \\
\hline & $\begin{array}{l}\text { Sig. (2- } \\
\text { tailed) }\end{array}$ & .000 \\
\hline & $\mathrm{N}$ & 189 \\
\hline \multirow[t]{3}{*}{ Pay and benefit } & Correlation & $.711^{* *}$ \\
\hline & $\begin{array}{l}\text { Sig. (2- } \\
\text { tailed) }\end{array}$ & .000 \\
\hline & $\mathrm{N}$ & 189 \\
\hline \multirow[t]{3}{*}{ Job security } & Correlation & $.599^{* *}$ \\
\hline & $\begin{array}{l}\text { Sig. (2- } \\
\text { tailed) }\end{array}$ & .000 \\
\hline & $\mathrm{N}$ & 189 \\
\hline \multirow[t]{3}{*}{ Supervision } & Correlation & $.675^{* *}$ \\
\hline & $\begin{array}{l}\text { Sig. (2- } \\
\text { tailed) }\end{array}$ & .000 \\
\hline & $\mathrm{N}$ & 189 \\
\hline
\end{tabular}

Source; author, 2018 


\section{Regression Analysis}

Multiple regression analysis (as seen in table-3- ) employed to examine the research hypotheses, however, the findings revealed the followings:

- It was found the P-value between employee achievement and organizational performance $=.000$, therefore, the first research hypothesis is supported which stated that "Employee achievement as a motivation factor has a significant and positive role on organizational performance".

- It was found the P-value between growth and organizational performance $=.000$, therefore, the second research hypothesis is supported which stated that "Growth as a motivation factor has a significant and positive role on organizational performance".

- It was found the P-value between recognition and organizational performance $=.000$, therefore, the third research hypothesis is supported which stated that "Recognition as a motivation factor has a significant and positive role on organizational performance".

- It was found the P-value between working condition and organizational performance $=.000$, therefore, the fourth research hypothesis is supported which stated that "Work condition as a motivation factor has a significant and positive role on organizational performance".

- It was found the P-value between company policy and organizational performance $=.000$, therefore, the fifth research hypothesis is supported which stated that "Company policy as a motivation factor has a significant and positive role on organizational performance".

- It was found the P-value between pay and benefit with organizational performance $=.000$, therefore, the sixth research hypothesis is supported which stated that " pay and benefit as a motivation factor has a significant and positive role on organizational performance".

- It was found the P-value between job security with organizational performance $=.000$, therefore, the seventh research hypothesis is supported which stated that "job security as a motivation factor has a significant and positive role on organizational performance".

- It was found the P-value between supervision with organizational performance $=.000$, therefore, the eighth research hypothesis is supported which stated that "Supervision as a motivation factor has a significant and positive role on organizational performance". 
Table 3 Regression Analysis

\begin{tabular}{cccccc}
\hline Model & \multicolumn{2}{c}{$\begin{array}{c}\text { Unstandardize } \\
\text { d Coefficients }\end{array}$} & $\begin{array}{c}\text { Standardize } \\
\text { d } \\
\text { Coefficients }\end{array}$ & t & Sig. \\
\cline { 2 - 5 } & B & $\begin{array}{c}\text { Std. } \\
\text { Error }\end{array}$ & Beta & \\
\cline { 1 - 4 } (Constant) & 2.134 & .067 & & 17.02 & .000 \\
\hline Achievement & .501 & .029 & .511 & 2.694 & .000 \\
\hline Growth & .589 & .012 & .597 & 1.781 & .000 \\
\hline Recognition & .732 & .011 & .741 & 1.539 & .000 \\
\hline Working & .541 & .022 & .556 & 3.715 & .000 \\
\hline condition & .602 & .034 & .611 & 2.347 & .000 \\
\hline Company policy & .699 & .024 & .708 & 1.491 & .000 \\
\hline Pay and benefit & .596 & .091 & .603 & 2.784 & .000 \\
\hline Job security & .631 & .037 & .642 & 1.847 & .000 \\
\hline Supervision & & & &
\end{tabular}

a. Dependent Variable: Organizational Performance

Source; author, 2018

\section{DISCUSSIONS}

This paper investigated worker motivation as related with labors' desires concerning their activity performance rewards, correspondence encounters with their chief, and the valence that the labors ascribe to conceivable performance rewards. The Energy and dynamism measurement of worker motivation referred to the degree to which labors are spurred by a significant workload and fortifying work content, by the need to make progress, maintain a strategic distance from disappointment and exercise specialist in a focused workplace and by a work environment requesting due accentuation on business development and improvement. Be that as it may, because of different angle, for example, doubt on labors, financial issues, venture of additional exertion and more noteworthy level of uncertainty and equivocalness, administrators are unwilling to upgrade the work put. A propelled worker is responsive of the unmistakable objectives and destinations he/she should accomplish, in this manner he/she coordinates its endeavors toward that path. Mikkelsen, et al., (2017) announced that inspiration plans an education sectors more fruitful on the grounds that incited labors are continually searching for enhanced practices to complete a work, so it is basic for education sectors to convince inspiration of their labors (Njoroge \& Yazdanifard, 2014). These days, education sectors are utilizing new advances and scaling back the quantities of laborers, outsourcing or utilizing impermanent specialists so as to spare cost. 
The education sectors have own structure and objectives. One's part is characterized by the capacity one performs in light of the desires of the huge individuals from the education sectors. By additionally understanding this, education sectors can spare a huge measure of cash. Labors being human as they are have to do their best work even in strenuous conditions, which could be considered as one of their most steady and oily difficulties and this can be made conceivable through inspiring them. Labor inspiration is one of the approaches of chiefs to increment strong occupation administration among workers in education sectors (Kuranchie-Mensah, et al., 2016). This expansion in profitability will enhance benefits and furthermore prompt more dedicated workers since they have more put resources into the education sectors by applying more exertion. Keeping in mind the end goal to maintain a strategic distance from underestimation and supporting its upper hand, education sectors today are required to adjust to practical motivational systems, that have sealing comes about, in order to accomplish its objective, more noteworthy levels of abilities, duty and knowledge of labors are required and education sectors need to make a gigantic measure of venture. Labors who are more inspired through clear, reasonable, and by and by profitable reward desires will work harder for the education sectors, subsequently expanding efficiency. This circumstance can trigger a negative effect on labors' inspiration since they learn about that organizations swing to be less faithful and trustworthy to them. The requirements and intentions related with this measurement were essentially and decidedly identified with all parts of occupation fulfillment, specifically to work qualities, matters including compensation and advantage structures, and authoritative working. Performance of workers at the center administration level relies upon the prevailing society with respect to how much centrality is connected to the parts of labors at the center administration level.

\section{CONCLUSION}

The examination discovered wellbeing need under occupation fulfillment to be the first vital motivational factor and that the motivational esteem put on a factor may shift starting with one worker then onto the next. Hierarchical reward rehearses and the inspiration framework has a great deal to do with deciding labor turnover. At the point when labors see that, for example, they are not being compensated all around ok for the work that they are doing, they are probably going to take up an offer in another organization. Inspiration assumes a more critical part in dealing with an education sectors, for example, the impacts of HRM on advancement, 'better approach for working rule' for working relations. 
Such discoveries upgrade our comprehension of worker inspiration and give a beginning stage to printing ventures that may see it fit to outline or overhaul their labors' motivational structures or factors for better hierarchical development. It is recognized that making workers' inspiration isn't a simple errand for any printing industry, however utilizing review comes about like this one may manage the business the correct way, which could have a mess of effect for both the business and labor to accomplish amazing authoritative development. Labors' discernments that kindred workers who are at a similar rank are remunerated more, is a solid factor that prompts loss of inspiration for these labors in so much that they feel that they are not entirely in charge of the undertakings that they are formally doled out. Having focused on the significance of a decent compensation approach on the performance of laborers and the various types of reward that can impact specialists to perform better on an occupation, this investigation can accordingly be seen a call for businesses feeling of sense of duty regarding set up fitting motivation arrange for that will urge laborers to be more intentional and enhance their performance. Performance, as a field of study, is a well-known point in HRM after some time. It is critical for an organization to design, oversee and compensate the performance.

\section{REFERENCES}

Ahmad, F., Abbas, T., Latif, S., \& Rasheed, A. (2014). Impact of transformational leadership on employee motivation in telecommunication sector. Journal of management policies and practices, 2(2), 11-25.

Alnawafleh, E. A. T., Halim, M. S. B. A., \& Tambi, A. M. B. A. (2018). The Impact of Human Resource Management Practices, Organizational Culture, Motivation and Knowledge Management on Job Performance with Leadership Style as Moderating Variable in the Jordanian Commercial Banks Sector. Journal of Reviews on Global Economics, 6, 477-488.

Devito, L., Brown, A., Bannister, B., Cianci, M., \& Mujtaba, B. (2016). Employee Motivation based on the Hierarchy of Needs, Expectancy and the TwoFactor Theories Applied with Higher Education Employees. International Journal of Advances in Management, Economics and Entrepreneurship, 3(1), 20.

Gopal, R., \& Chowdhury, R. G. (2014). Leadership styles and employee motivation: An empirical investigation in a leading oil company in India. International journal of research in business management, 2(5), 110. 
Jensen, J. D. (2018). Employee Motivation: A Leadership Imperative. International Journal of Business Administration, 9(2), 88-93. Jin, M. H., McDonald, B., \& Park, J. (2018). Does Public Service Motivation Matter in Public Higher Education? Testing the Theories of PersonOrganization Fit and Organizational Commitment Through a Serial Multiple Mediation Model. The American Review of Public Administration, 48(1), 82-97.

Khuong, M. N., \& Hoang, D. T. (2015). The effects of leadership styles on employee motivation in auditing companies in Ho Chi Minh City, Vietnam. International Journal of Trade, Economics and Finance, 6(4), 210.

Kim, S. (2018). Public Service Motivation, Organizational Social Capital, and Knowledge Sharing in the Korean Public Sector. Public Performance \& Management Review, 41(1), 130-151.

Kuranchie-Mensah, E. B., \& Amponsah-Tawiah, K. (2016). Employee motivation and work performance: A comparative study of mining companies in Ghana. Journal of industrial Engineering and Management, 9(2), 255.

Lau, C. M., \& Roopnarain, K. (2014). The effects of nonfinancial and financial measures on employee motivation to participate in target setting. The British accounting review, 46(3), 228-247.

Mikkelsen, M. F., Jacobsen, C. B., \& Andersen, L. B. (2017). Managing employee motivation: Exploring the connections between managers' enforcement actions, employee perceptions, and employee intrinsic motivation. International Public Management Journal, 20(2), 183-205.

Mikkelsen, M. F., Jacobsen, C. B., \& Andersen, L. B. (2017). Managing employee motivation: Exploring the connections between managers' enforcement actions, employee perceptions, and employee intrinsic motivation. International Public Management Journal, 20(2), 183-205.

Mills, M. J. (2017). Incentivizing around the globe: Educating for the challenge of developing culturally considerate work motivation strategies. Management Teaching Review, 2(3), 193-201.

Njoroge, C. N., \& Yazdanifard, R. (2014). The impact of social and emotional intelligence on employee motivation in a multigenerational workplace. International Journal of Information, Business and Management, 6(4), 163.

Porter, T. H., Riesenmy, K. D., \& Fields, D. (2016). Work environment and employee motivation to lead: Moderating effects of personal characteristics. American Journal of Business, 31(2), 66-84.

Selvarajan, T. T., Singh, B., \& Solansky, S. (2018). Performance appraisal fairness, leader member exchange and motivation to improve performance: A study of US and Mexican employees. Journal of Business Research, 85, 142-154. 
Siddiqui, N. N., \& Bisaria, G. (2018). Innovative Techniques of Motivation for Employee Retention in Aviation Industry. ANVESHAK-International Journal of Management, 7(1), 136-151.

Simajuntak, S., \& Tobing, S. J. (2018). The Effect of Motivation and Organizational Culture on Employee Performance In Pt. Lbum. Fundamental Management Journal, 2(2), 63-70.

Subramony, M., Segers, J., Chadwick, C., \& Shyamsunder, A. (2018). Leadership development practice bundles and organizational performance: The mediating role of human capital and social capital. Journal of business research, 83, 120-129.

Vakharia, N., Vecco, M., Srakar, A., \& Janardhan, D. (2018). Knowledge centricity and organizational performance: an empirical study of the performing arts. Journal of Knowledge Management.

Van Iddekinge, C. H., Aguinis, H., Mackey, J. D., \& DeOrtentiis, P. S. (2018). A meta-analysis of the interactive, additive, and relative effects of cognitive ability and motivation on performance. Journal of Management, 44(1), 249-279.

Wang, M. (2018). Effects of Organizational Learning Environment on Employees' Motivation to Use Performance-Oriented e-Learning. In E-Learning in the Workplace (pp. 161-180). Springer, Cham.

Wen Lim, H., Li, N., Fang, D., \& Wu, C. (2018). Impact of Safety Climate on Types of Safety Motivation and Performance: Multigroup Invariance Analysis. Journal of Management in Engineering, 34(3), 04018002.

Zameer, H., Ali, S., Nisar, W., \& Amir, M. (2014). The impact of the motivation on the employee's performance in beverage industry of Pakistan. International Journal of Academic Research in Accounting, Finance and Management Sciences, 4(1), 293-298. 